\title{
NEW THICK-FILM MICROWAVE ELEMENTS FOR MICROWAVE INTEGRATED CIRCUITS
}

\author{
JANUSZ J. GONDEK and MAREK A. WÓJCICKI \\ Microelectronics Department, Institute of Electronics Mining and Metallurgical University, \\ ul. Czarnowiejska 78, 30-054 Kradow, Poland. \\ and \\ JAN CABER \\ Tokyo Institute of Technology, Japan. \\ (Received May 6, 1981; in final form August 12, 1982)
}

\begin{abstract}
The realisation of microwave integrated circuits consisting of numerous elements and components, both passive and active, takes place in steps. Initially, experimental constituent elements are designed and constructed, and only after it is found that they satisfy the operating conditions, can they be integrated into a sub-system. As a result of this we obtain complicated Microwave Integrated Circuits (MICs). Initially however one has to construct basic MIC elements such as: resonators, filters, couplings, $Y$ branch joints, circulators, etc. During research over several years carried out at the Microelectronics Department, Institute of Electronics, of the Mining and Metallurgical University of Kraków and devoted to the application of thick-film technology to MIC, the authors have devised and constructed several microwave elements using strip-lines and this paper reports of the results of their studies.

Pastes produced by DU PONT/USA were used. New mathematical models for designing thick-film microwave elements have been elaborated using computer techniques. These programmes have differed from analogous ones for MIC realized by thin-film technology can be adapted, after certain modifications, to the realisation of MIC. The authors have introduced new technological operations, not used so far, to the technological process. This has made possible the production of thick-film microwave elements with parameters comparable to those obtained in thin-film technology.
\end{abstract}

\subsection{THICK-FILM MICROWAVE ELEMENTS $2,3,5,6$}

After reviewing the relevant literature ${ }^{2,3,5}$ and after making a number of investigations of our own $\mathrm{ow}^{5,6}$ in the area of MIC thick-film constructions, it can be stated that at the present time it is difficult to speak of a general method of microwave integrated circuit construction. The method will depend on the technique of realisation, as well as on the type of circuit being designed. Assuming that the technology of production and the concept of the circuit - meeting given utilisation requirements and electrical parameters are laid down, the realization of the circuit resolves itself into the design and preliminary construction of its constituent elements and microwave circuits. Only after obtaining information about the correctness of the particular designs and correcting them, if necessary, can one undertake to integrate the whole circuit. The authors have designed basic microwave elements such as: microwave resonators, hybrid rings, narrow and broadband filters, $3 \mathrm{~dB}$ couplers, circulators, etc., and they have been constructed using thickfilm technology. The measurement of the frequency characteristics has been undertaken using a circuit Network Analyser, (Hewlett-Packard, type HP-8410S).

\footnotetext{
TPaper originally presented at the 31 st Electronic Components Conference held at Atlanta, Georgia, U.S.A.
} 


\subsection{THICK-FILM BROAD-BAND-PASS FILTER}

\section{Required Parameters of the Filter}

1. Pass-band centre frequency $\mathrm{f}_{0}=6 \mathrm{GHz}$

2. Relative width of band $w=0,5$

3. Ripple inside pass band $=0,1 \mathrm{~dB}$

4. Load impedance $Z_{A}=Z_{B}=50 \Omega$

5. Attenuation at frequency $8 \mathrm{GHz}=30 \mathrm{~dB}$

A filter, a section from which is shown in Figure 1, was chosen. Such a filter has the following properties:

- it has a second pass band at frequency $3 \omega_{0}$

- it has first order attenuation poles at frequency $\omega=0$ and $\omega=2 \omega_{0}$

- it can be realised for w from 0,4 to 0,7 and above.

Meeting the last requirement of the design on the basis of the formula by Matthaei et al., ${ }^{8}$ the number of reactance elements of the filter was determined as being equal to 8 i.e. $(\mathrm{N}=8)$. The parameters of the filter were computed, using previous results. ${ }^{8}$

The models of the microwave filters were made with the use of standard thick-film technology. Ceramic substrates made of $96 \%$ alumina ceramics were used and their dimensions were $50 \times 30 \times 0,7 \mathrm{~mm}$.

The substrates were initially sorted on the basis of their geometrical dimensions, mainly the thickness $h(0,7 \mathrm{~mm})$ and the roughness. The tolerance of $h$ was $\pm 10 \mu \mathrm{m}$ and a surface roughness factor $R_{a}$ of less than or equal to $0,9 \mu \mathrm{m}$ was required.

$\mathrm{Du}$ Pont pastes were used for printing. These were:-

1. Pt-Ag - DP9780 or DP9770 ${ }^{\dagger}$

2. $\mathrm{Au}-\mathrm{DP} 9791$

3. $\mathrm{Ag}-\mathrm{DP} 8032$

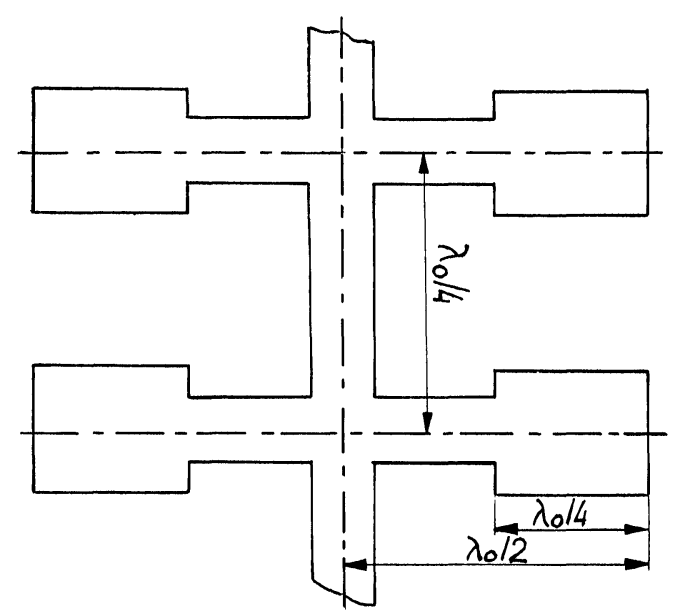

FIGURE 1 Structure of microwave broad-band-pass filter.

\footnotetext{
${ }^{\dagger}$ These two pastes differ only in final thickness and solderability and are interchangeable with regard to the microwave properties.
} 
Microstrip constructions of the filter were printed using the Pt-Ag or the $\mathrm{Au}$ pastes in single layers, and the $\mathrm{Ag}$ paste was used for a double layer printing of a ground plane on the reverse side of the substrate. By double printing, the resistance of the ground plane cold be reduced to $1.5-2.0 \mathrm{~m} \Omega / \mathrm{sq}$. Precise screening was obtained using the orientation of the photomasks with the screen wires. The models of the filters were printed using either 260 Mesh or 330 Mesh screens.

The results of the measurements of attenuation characteristics as a function of frequency are presented in Figures 2 to 5.

As expected from the design, the filter works in the microwave band $S$ and in the auxiliary bands $\mathrm{G}$ and $\mathrm{C}$. The measured pass characteristics are shifted somewhat in the direction of lower frequencies by about $0,1 \mathrm{GHz}$ compared with the theoretical curve. This is a result of the open ends of the resonators. The literature to date does not give any precise formula for computing such an effect.

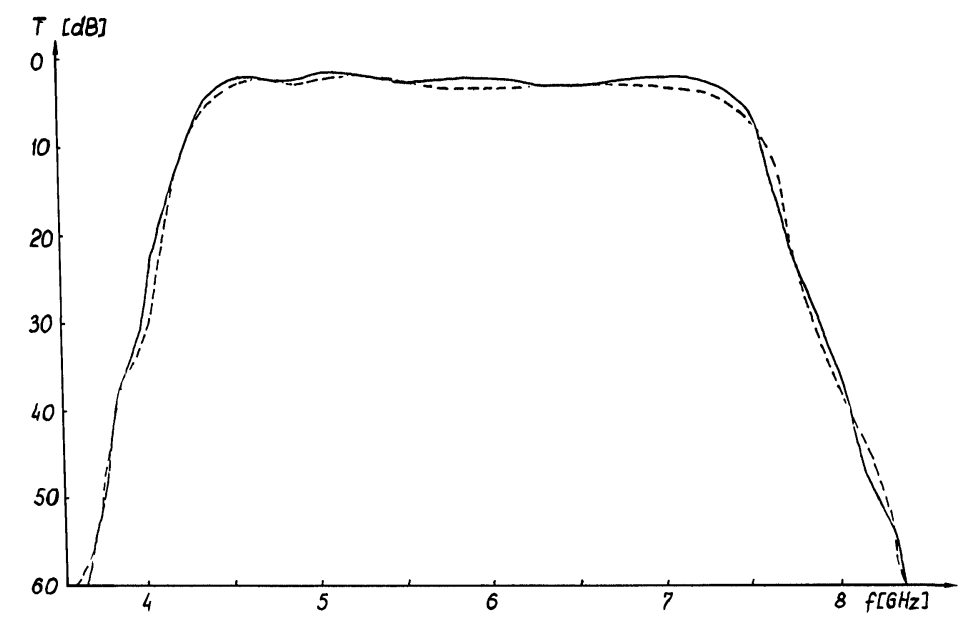

FIGURE 2 Characteristics of broad band filter. Transmittance (T) vs frequency Paste: DP9791, (Au); Screen, 330 Mesh.

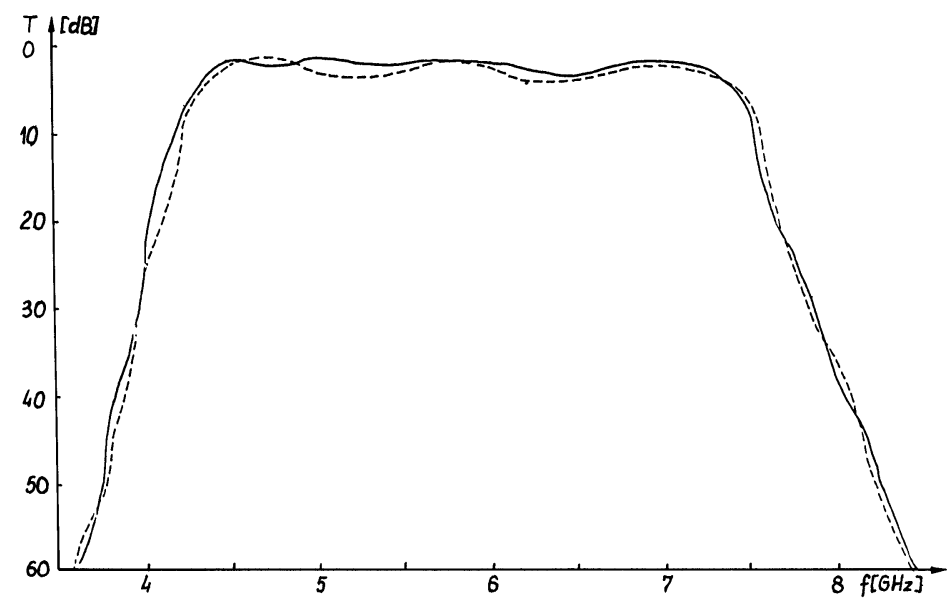

FIGURE 3 Characteristic of broad band filter Transmittance (T) vs Frequency. Paste: DP9791 (Au); Screen, 260 Mesh. 


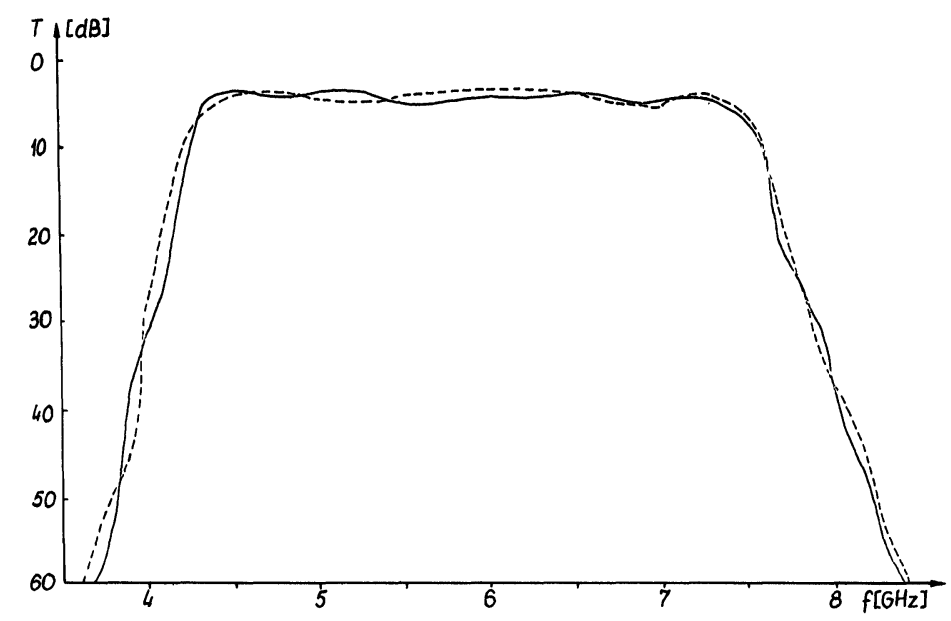

FIGURE 4 Characteristic of broad band filter Transmittance (T) vs Frequency Paste: DP9780 (Pt-Ag). Screen, 330 Mesh.

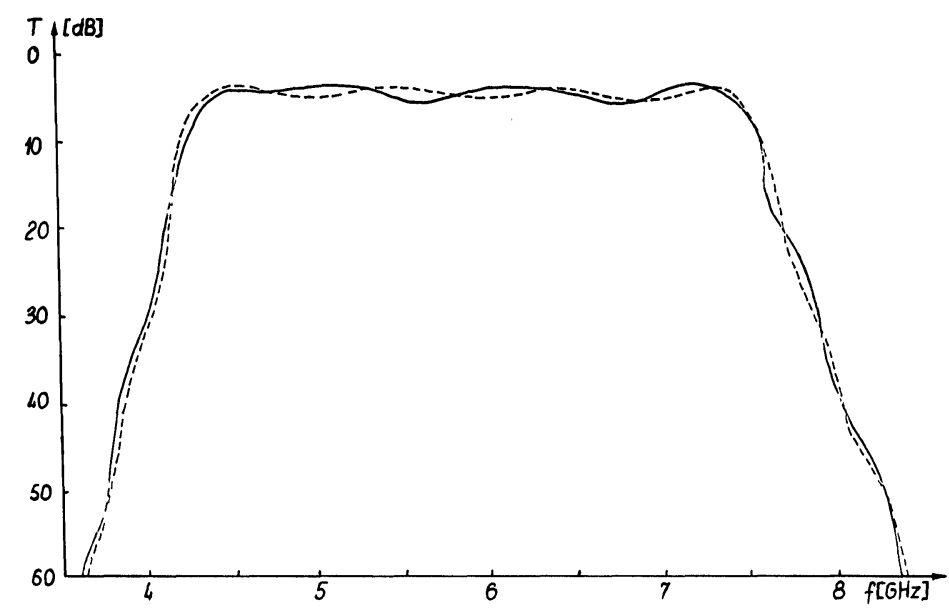

FIGURE 5 Characteristic of broad band filter. Transmittance (T) vs Frequency. Paste: DP9780 (Pt(Pt-Ag). Screen, 260 Mesh.

The basic parameters of the filters obtained from the characteristics given in Figures 2 to 5 are summarized in Table $\mathrm{I}$. The continuous lines represent $\mathrm{T}+3 \mathrm{~S}$, where $\mathrm{T}$ is the mean value of the transmittance and $S$ is the mean statistical duration.

As can be seen from the results of the measurements presented in Table I, attenuation for frequency $f=8 \mathrm{GHz}$ is somewhat greater than expected $(30 \mathrm{~dB})$. The pass band is however satisfactory with an error of $\sim 3 \%$. The ripple in the pass band is greater than by expected an order of magnitude. This last effect is a result of the losses due to the mismatching of the ASL (Asymmetrical Lines) to the load with $\mathrm{Z}_{0}=50 \Omega$ and to the effect of the coaxial joints.

These problems have been investigated in detail and are reported elsewhere. ${ }^{5,6}$ After taking into consideration the so-called surface covering coefficient $\mathrm{K}_{\mathrm{s}}{ }^{6}{ }^{6}$ the losses can be reduced by $80 \%$. This has been checked for circular resonators. The value of ripple in the pass band is also essentially influenced by:- 
TABLE I

Basic parameters of the filters

\begin{tabular}{lllll}
\hline Fig. & $\begin{array}{l}\text { Paste } \\
\text { Screen }\end{array}$ & $\begin{array}{l}\text { Pass } \\
\text { Band GHz }\end{array}$ & $\begin{array}{l}\text { Attenuation } \\
\text { for } \mathrm{f}=8 \mathrm{GHz} \text { dB }\end{array}$ & $\begin{array}{l}\text { Ripple } \\
\mathrm{dB}\end{array}$ \\
\hline 2 & $\begin{array}{l}\text { DP9791 } \\
330 \text { Mesh }\end{array}$ & $4,3-7,4$ & 35 & 0,8 \\
3 & $\begin{array}{l}\text { DP9791 } \\
260 \text { Mesh }\end{array}$ & $4,4-7,4$ & 36 & 1,8 \\
5 & $\begin{array}{l}\text { DP9780 } \\
330 \text { Mesh }\end{array}$ & $4,3-7,4$ & 36 & 1,1 \\
5 & $\begin{array}{l}\text { DP9780 } \\
260 \text { Mesh }\end{array}$ & $4,4-7,4$ & 36 & 2,0 \\
\hline
\end{tabular}

(i) the repeatability of the technological process, especially the operation of mask manufacture and screening

(ii) the roughness of the edges of the microstrips produced by the screening.

While the repeatability of the technological process can be kept within certain limits, the solving of point (ii) is a more difficult matter. A solution has been proposed by Gondek and Nowak. ${ }^{7}$ They introduced into the process an additional operation; dimensional trimming of the microwave strip constructions with the use of a laser, an electron beam or precise air abrasion.

\subsection{THICK-FILM NARROW-BAND-PASS FILTER}

\section{Required Parameters of the Filter}

1. Pass-band center frequency $\mathrm{f}_{0}=4 \mathrm{GHz}$

2. Absolute width of band $\mathrm{B}=450 \mathrm{MHz}$

3. Ripple inside pass band $0,1 \mathrm{~dB}$

4. Load impedance $Z_{A}=Z_{B}=50 \Omega$

5. Attenuation at $4,4 \mathrm{GHz}=40 \mathrm{~dB}$

Figure 6 shows the structure that was chosen.

The parameters of the filter were computed on the basis of the data given by Matthaei et al. ${ }^{8}$ As before, Du Pont pastes were used to make the models. ${ }^{2}$ The results of the measurements of the transmission characteristics are given in Figures 7 to 10.

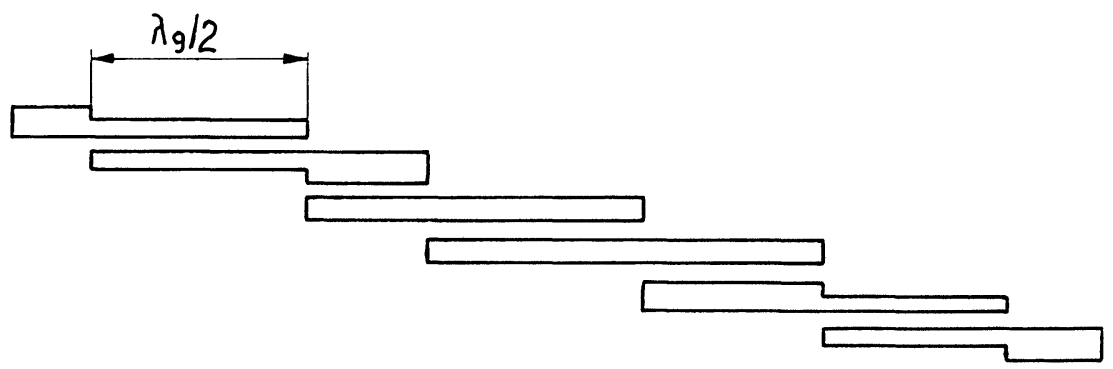

FIGURE 6 Structure of narrow-band-pass filter. 


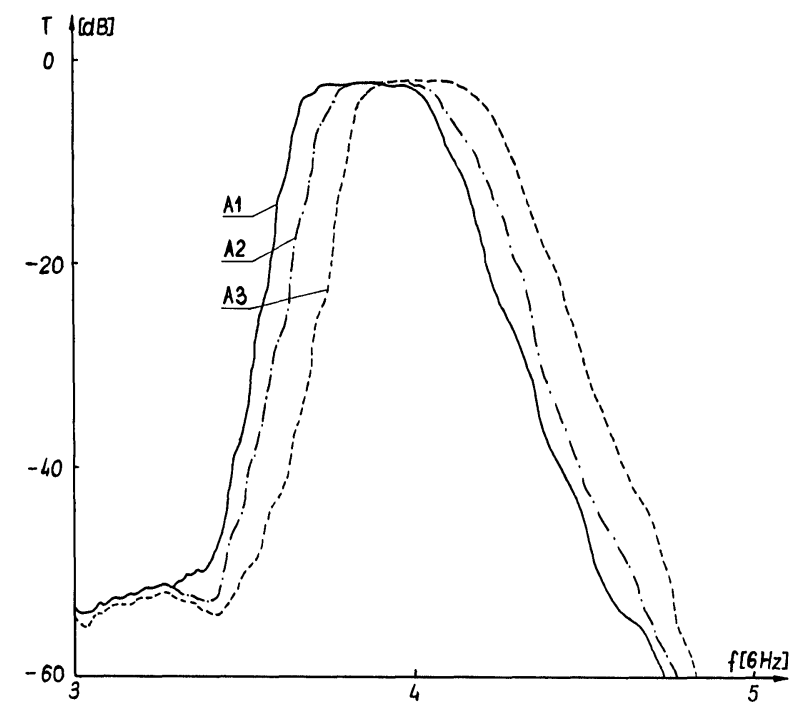

FIGURE 7 Characteristics of narrow band filters. Transmittance (T) vs Frequency Paste: DP9770 (Pt-Ag), Screen A1-220 Mesh, A2-260 Mesh, A3-330 Mesh.

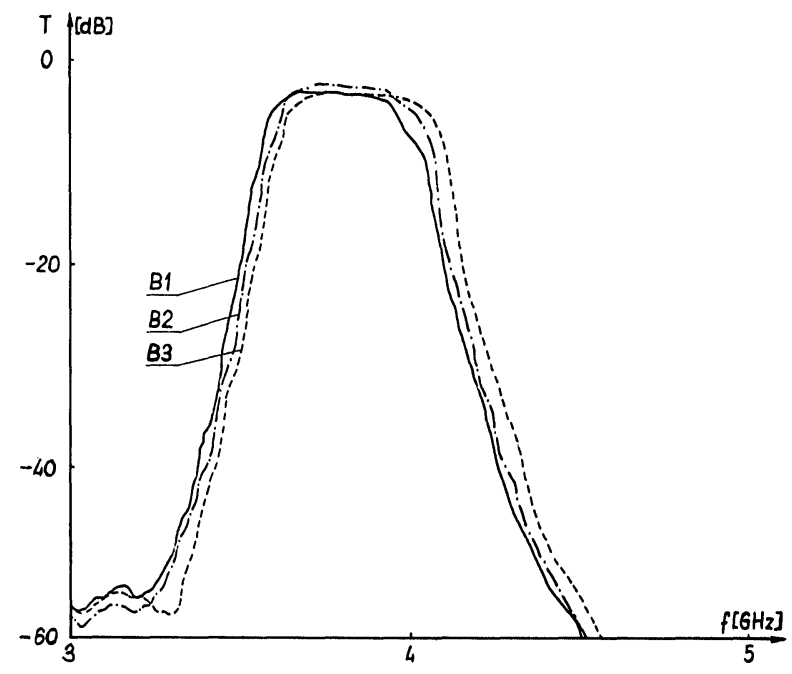

FIGURE 8 Characteristics of narrow band filter. Transmittance (T) vs Frequency Paste: DP9791 (Au), Screen: B1-220 Mesh, B2-260 Mesh.

The basic parameters of the filters obtained from the transmission characteristics are summarized in Table II.

On analysing the results given in Table II one can see that in all the models of the filters the mid-band frequency $f_{0}$ is shifted in the direction of lower frequencies, on average by 0,1 to $0,3 \mathrm{GHz}$.

Figure 9 shows the standing wave ratio (SWR) obtained as a function of frequency for the filters shown in Figure 7, and Figure 10 shows similar curves for the filters shown in Figure 8. 


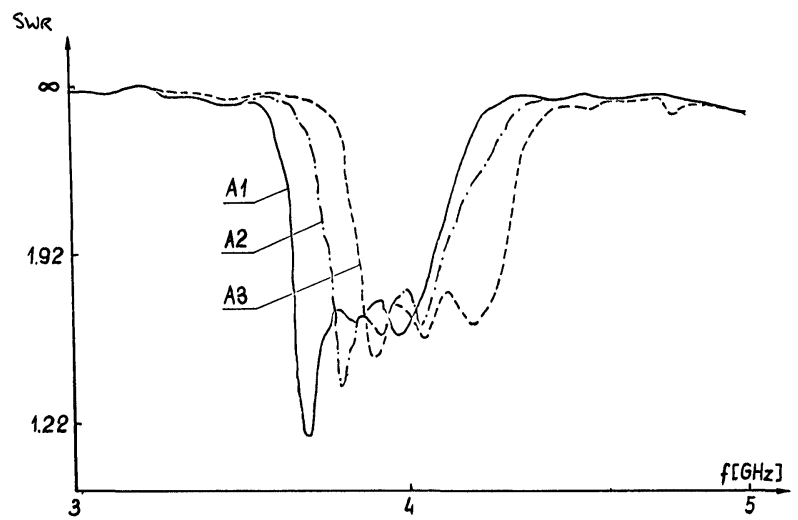

FIGURE 9 Characteristics of narrow band filters. SWR vs Frequency. Paste: DP9770 (Pt-Ag). Screen :A1-220 Mesh; A2-260 Mesh, A3-330 Mesh.

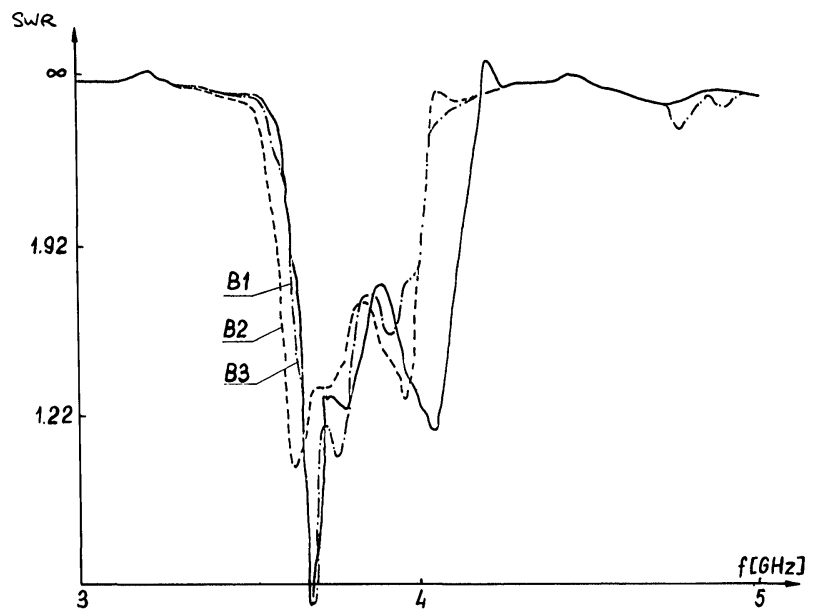

FIGURE 10 Characteristics of narrow band filters. SWR vs Frequency Paste: DP9791 (Au) Screen: B1-220 Mesh, B2-260 Mesh, B3-330 Mesh.

TABLE II

Basic parameters of the filters

\begin{tabular}{llllll}
\hline Fig. & $\begin{array}{l}\text { Paste, } \\
\text { Screen }\end{array}$ & $\begin{array}{l}\text { Mid-band } \\
\text { Frequency } \\
\mathrm{GHz}\end{array}$ & $\begin{array}{l}\text { Pass-band } \\
\mathrm{B}, \\
\mathrm{MHz}\end{array}$ & $\begin{array}{l}\text { Attenuation } \\
\text { for } \mathrm{f}=4,4 \\
\mathrm{GHz}, \mathrm{dB}\end{array}$ & $\begin{array}{l}\text { Ripple in } \\
\text { Pass-band } \\
\mathrm{dB}\end{array}$ \\
\hline 8 & $\begin{array}{l}\text { DP9791 } \\
\text { 330 Mesh }\end{array}$ & 3,85 & 460 & 47,0 & 0,8 \\
7 & $\begin{array}{l}\text { DP9770 } \\
330 \text { Mesh }\end{array}$ & 4,035 & 420 & 30,0 & 0,66 \\
8 & $\begin{array}{l}\text { DP9791 } \\
220 \text { Mesh }\end{array}$ & 3,8 & 400 & 50,6 & 0,6 \\
7 & $\begin{array}{l}\text { DP9770 } \\
220 \text { Mesh }\end{array}$ & 3,46 & 400 & 37,7 & 1,1 \\
\hline
\end{tabular}


The results obtained are comparable to those obtained with broad-band filters. It is also apparent that as far as smaller losses (narrower band) are concerned, it is more expedient to use screens with greater meshes, e.g. 220 Mesh, in the printing. The cases, A2 and B2, show this as they depict the use of screens with a larger mesh size. It can also be seen, that the use of screens with a large mesh size $(\mathrm{N}=260$ Mesh) causes the shifting of the pass-band center frequency $f_{0}$ in the direction of higher frequencies. The explanation of the phenomenon has been given in other papers. ${ }^{3,5,6}$

From an analysis of the SWR characteristics it is apparent that DP9791 paste (for different screens).

The results obtained can probably be explained as the result of not taking into consideration the $\mathrm{K}_{\mathrm{s}}$ coefficient takes into account the kind of screen and conductive paste used.

\subsection{THICK-FILM HYBRID RING}

Directional couplers constitute a large group of passive microwave circuits with four inputs, i.e. "fourgates" which have a common characteristic of directional transmission and of the division of power of the input signals. One of the kinds of "fourgates" is the hybrid ring whose construction is shown in plane view in Figure 11.

Data for the Design of a Hybrid Ring to be Constructed with the use of the Thick-film Technology:

1. Working frequency $\mathrm{f}_{0}=5 \mathrm{GHz}$

2. Wave impedance $Z_{0}=50 \Omega$

3. $3 \mathrm{~dB}$ coupler

4. Substrate material: alumina ceramics $96 \%$ with dimensions $50 \times 30 \times 0,7 \mathrm{~mm}$.

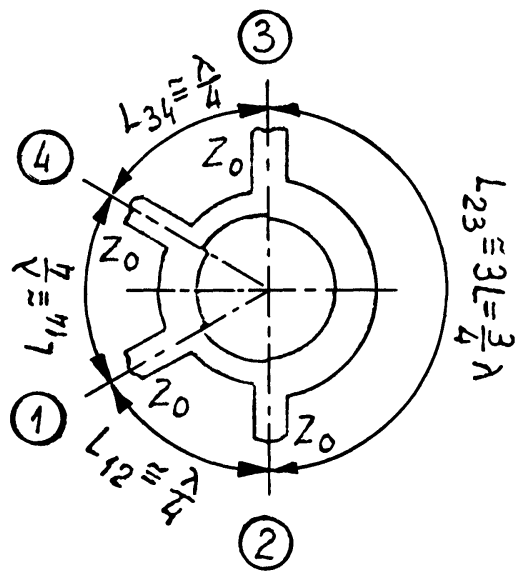

FIGURE 11 Structure of hybrid ring. 
With the use of the formulae given in ref. ${ }^{5,8}$ the following results were obtained:

$$
\begin{array}{ll}
\lambda_{0}=6 \mathrm{~cm} & \alpha_{1}=59,8^{\circ} \\
\epsilon_{\mathrm{ef}}=6,15 & \alpha_{2}=180,6^{\circ} \text { ) } \text { ) angular apertures } \\
\lambda_{\mathrm{g}}=2,419 \mathrm{~cm} & \mathrm{Z}_{1}=\mathrm{Z}_{2}=70,71 \Omega \\
\mathrm{C}=3,629 \mathrm{~cm} \text { (length of ring) } \mathrm{w}_{\mathrm{ASL}}=0,7023 \mathrm{~mm} \\
\mathrm{R}=0,5778 \mathrm{~cm} \text { (radius of ring) } \mathrm{w}_{\mathrm{R}}=0,2975 \mathrm{~mm} \text { (of ring). }
\end{array}
$$

The hybrid ring was made with the use of thick-film technology and Du Pont pastes, numbers DP9780 (Pt-Ag) and DP9791 (Au).

The frequency characteristics of the models investigated are given in Figures 12 to 15 . The result of the measurement of the frequency characteristics of insulation, $\mathrm{J}$, are given in Tables III and IV.

\section{Analysis of Measurements Results:}

Comparing the results of the measurements with the design one can conceive that they diverge somewhat from the theoretical computations. One can observe a deviation of midband frequency $f_{0}$ in the direction of higher frequencies, both for rings made with the DP9791 and DP9780 pastes. This is especially notable in the insulation characteristics of the rings.

From the characteristics obtained it can be clearly seen that insulation between gates (e.g. 1-3) is clearly dependent on frequency, but it is higher for models made with the use of the DP9791 paste than for those made with the use of the DP9780 paste.

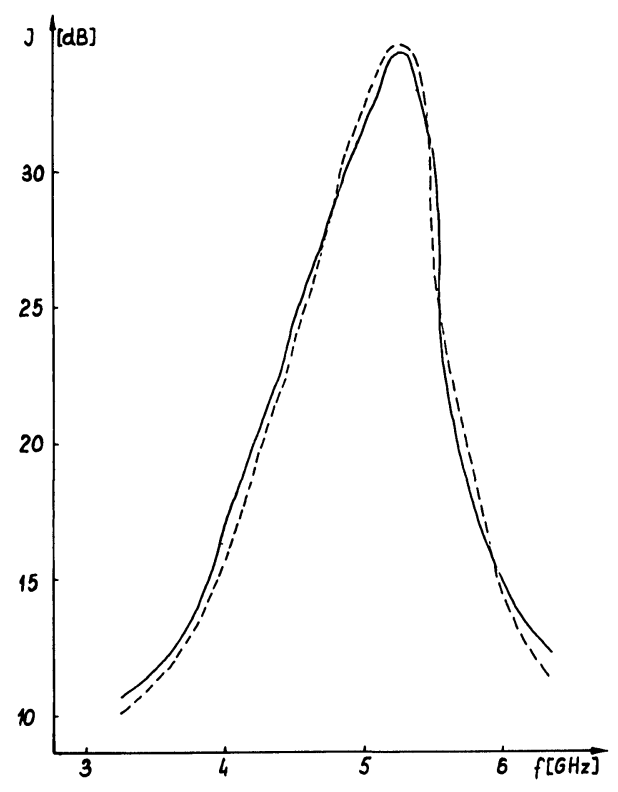

FIGURE 12 Frequency characteristics of insulation hybrid ring. Paste: DP9791 (Au): ... $330 \mathrm{Mesh},-260 \mathrm{Mesh}$.

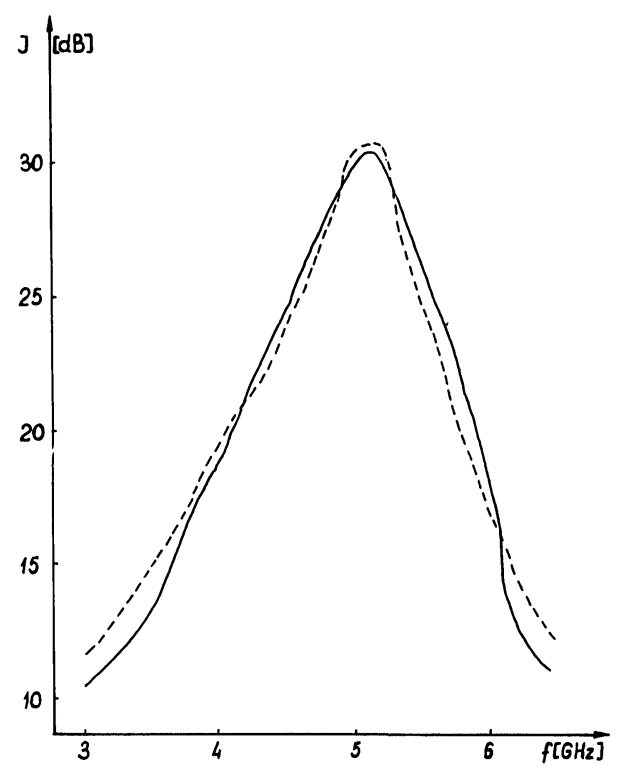

FIGURE 13 Frequency characteristics of insulation hybrid ring. Paste: DP9780 (Pt-Ag): .. 330 Mesh, - 260 Mesh. 


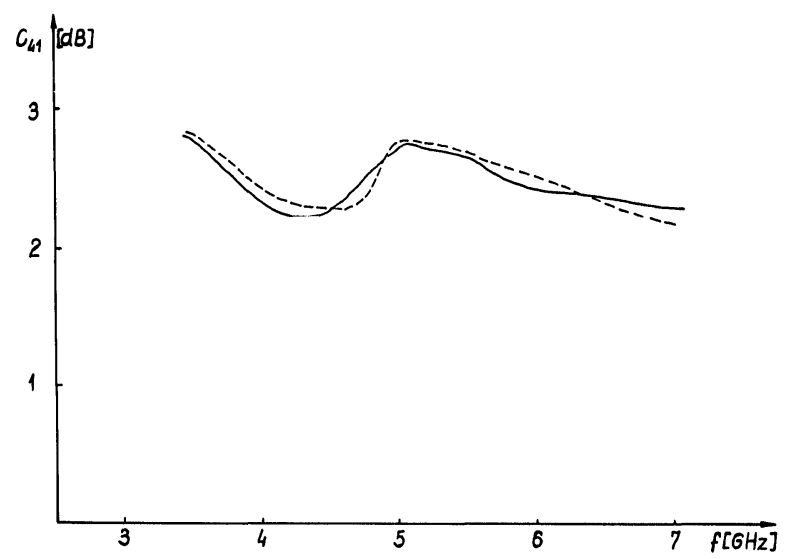

FIGURE 14 Frequency characteristics of $C_{41}$ hybrid ring. Paste: DP9791: - - 330 Mesh; - 260 Mesh.

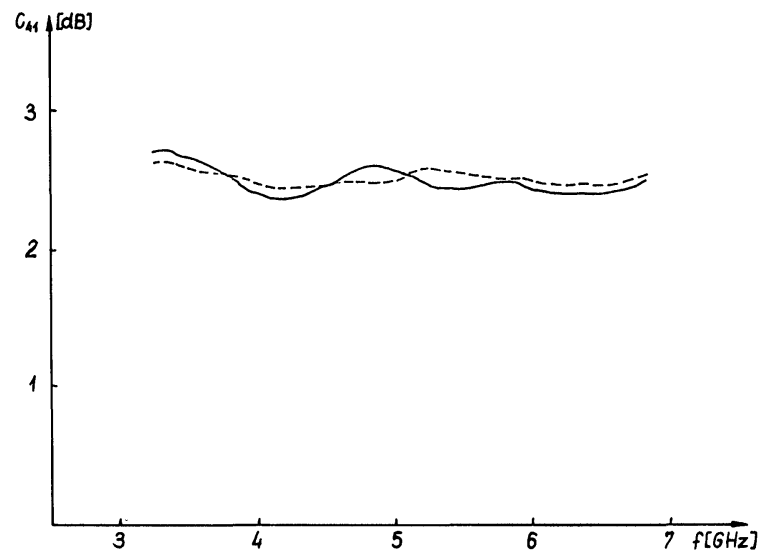

FIGURE 15 Frequency characteristics of $C_{41}$ hybrid ring. Paste: DP9780 - - 330 Mesh, - 260 Mesh.

Transmission characteristics, $\mathrm{C}_{21}$ or $\mathrm{C}_{41}^{\dagger}$, (Figures 14 and 15) show are more broadband than insulation characteristics of hybrid rings. Greater oscillations of the coupling is exhibited by models printed with the gold paste DP9791. In the models, for the printing of which the DP9780 paste was used, the oscillation of $\mathrm{C}_{41}$ is smaller, but the absolute value $\mathrm{C}_{41}$ is also smaller. Probably, as the coupling $\mathrm{C}_{41}$ decreases, the oscillation $\Delta \mathrm{C}_{41}$ will decrease for all types of conductive pastes. This seems to agree with the theory.

On comparing the frequency characteristics obtained, one can draw the conclusion that the use of the DP-9791 paste can give better parameters than the use of the platinum-silver paste DP-9780.

The coupling values obtained are somewhat lower than the assumed value of $3 \mathrm{~dB}$. This is probably a result of not taking into account the $\mathrm{K}_{\mathrm{s}}$ coefficient in the computation of the hybrid ring.

Nevertheless, the results of the measurements of the microwave element should be considered as satisfactory. A coupling ranging within $3 \mathrm{~dB}$ is very difficult to obtain by means of other types of couplers in MIC constructions. For directional couplers it is difficult to produce a coupling slot of the order $\mathrm{S}_{0}=50-200 \mu \mathrm{m}$, in thick-film technology.

\footnotetext{
${ }^{\dagger} \mathrm{C}_{21}$ and $\mathrm{C}_{41}$ are interchangeable because of the symmetry of a hybrid ring.
} 
TABLE III

Insulation parameters of a hybrid ring made with the use of DP9791( $\mathrm{Au})$ paste

\begin{tabular}{lll}
\hline $\begin{array}{l}\text { Frequency of } \\
\text { Measurement } \\
(\mathrm{GHz})\end{array}$ & Screen: 260 Mesh & Value of Insulation (dB) \\
\cline { 2 - 3 } & 17,4 & Screen: 330 Mesh \\
\hline 4,0 & 25,0 & 17,2 \\
4,5 & 29,0 & 25,1 \\
4,8 & 31,0 & 28,8 \\
4,9 & 32,0 & 31,1 \\
5,0 & 33,0 & 32,0 \\
5,1 & 33,7 & 33,0 \\
5,2 & 33,4 & 33,8 \\
5,3 & 26,1 & 33,4 \\
5,3 & 26,2 \\
\hline
\end{tabular}

TABLE IV

Insulation parameters of a hybrid ring made with the use of DP9780 (Pt-Ag) paste

\begin{tabular}{lll}
\hline & & $\begin{array}{c}\text { Value of insulation } \\
(\mathrm{db})\end{array}$ \\
\cline { 2 - 3 } $\begin{array}{l}\text { Frequency } \\
\text { of measurement } \\
(\mathrm{GHz})\end{array}$ & $\begin{array}{l}\text { Screen: } \\
\text { 260 Mesh }\end{array}$ & $\begin{array}{l}\text { Screen: } \\
330 \text { Mesh }\end{array}$ \\
\hline 4,0 & 19,0 & 18,8 \\
4,5 & 24,9 & 24,3 \\
4,8 & 28,2 & 28,0 \\
4,9 & 29,1 & 29,2 \\
5,0 & 30,0 & 30,1 \\
5,1 & 30,2 & 30,3 \\
5,2 & 29,1 & 28,9 \\
5,3 & 28,0 & 28,0 \\
5,5 & 25,7 & 25,2 \\
\hline
\end{tabular}

\subsection{THICK-FILM RING RESONATORS}

Ring resonators constitute quite a large group among resonators used in MIC. They have a simple construction and a high quality, higher than that of other strip resonators (e.g. rectangular). The advantages of these microwave elements prompted the present authors to make some models of ring resonators in thick-film technology. The suggestion was to make the designs of two ring resonators with different configurations. In the computation of ASL when coupled with the resonators, a computation programme was required. ${ }^{6}$

The following requirements and materials were noted:-

1. Characteristic impedance of ASL, $Z_{0}=50 \Omega$

2. Range of the frequency of work of ASL, $\Delta \mathrm{F}=1-15 \mathrm{GHz}$

3. Substrate material - alumina ceramic $96 \% \epsilon_{\mathrm{r}}=9,5$ with dimensions $50 \times 30 \times$ $0,5 \mathrm{~mm}$

4. Thickness of printed film $\mathrm{t}=15-20 \mu \mathrm{m}$

5. The resonator ring, ASL and shield to be made using Du Pont 9791 conductive paste. 
The construction parameters of ASL were computed with the use of a special computer programme (b) (Figure 16). The results of the computation of ASL according to the computer programme given below:-

$$
\begin{array}{ll}
\mathrm{Z}_{0}=49,9556 \Omega & \mathrm{w}_{\mathrm{EF}}=0,5039 \mathrm{~mm} \\
\mathrm{w}_{\mathrm{r}}=0,4749 \mathrm{~mm} & \epsilon_{\mathrm{EF}}=6,36 \\
\Delta \mathrm{w}_{\mathrm{r}}=0,116 \mathrm{~mm} & \mathrm{~h}=0,5 \mathrm{~mm} \\
\Delta \mathrm{w}=0,029 \mathrm{~mm} & \lambda_{\mathrm{g}}=2,98 \mathrm{~cm} \\
\mathrm{w}=0,5906 \mathrm{~mm} &
\end{array}
$$

With the parameters of ASL at hand, the authors proceeded to compute the dimensions of the ring resonators. Computer programmes prepared in Fortran 1900 language on the basis of the formulae given in ${ }^{5,6}$ were used.

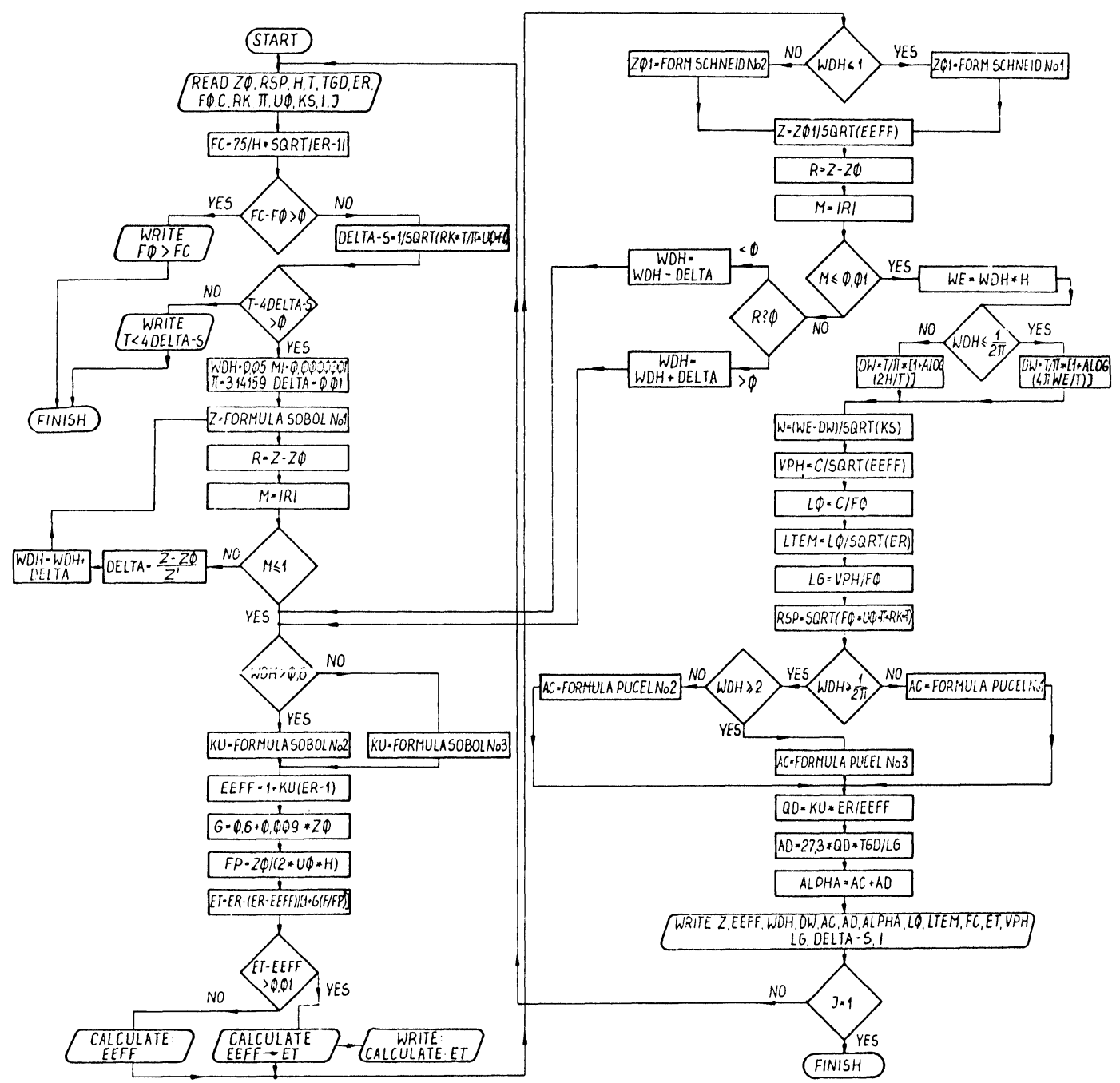

FIGURE 16 Computer program for ASL, ${ }^{6}$. 
The following electronic parameters of ring resonators were required:-

1. Resonant frequency $f_{0}$ in the topological version $I$ of the ring resonator $f_{0}=9 \mathrm{GHz}$

2. Resonant frequency in the topological version II $f_{0}=4 \mathrm{GHz}$

3. Characteristic impedance of resonators $Z_{0}=50 \Omega$

4. Substrate material - Alumina plates with dimensions $50 \times 30 \times 0,5 \mathrm{~mm}$ with $\epsilon_{\mathrm{r}}=9,5\left(96 \% \mathrm{Al}_{2} \mathrm{O}_{3}\right)$.

Fig. 17a and $\mathrm{b}$ present resonators designed for $\mathrm{h}=0,5 \mathrm{~mm}$.

\section{Analysis of Transmission Characteristics of Ring Resonators:}

Figure 18 presents a graph of transmittance vs frequency for the ring resonators under study after statistical data processing. (Number of samples $\geqslant 34$ ).

The result of the computation of $Q$ and attenuation, $\alpha$, are presented in Table 5.

The values obtained from the graph drawn with the broken line (curve no. 2) indicate inappropriate fixing of the resonators in the measurement cassette (bad contact). These are results of measurements of those resonators which were loosely fixed by direct

a)

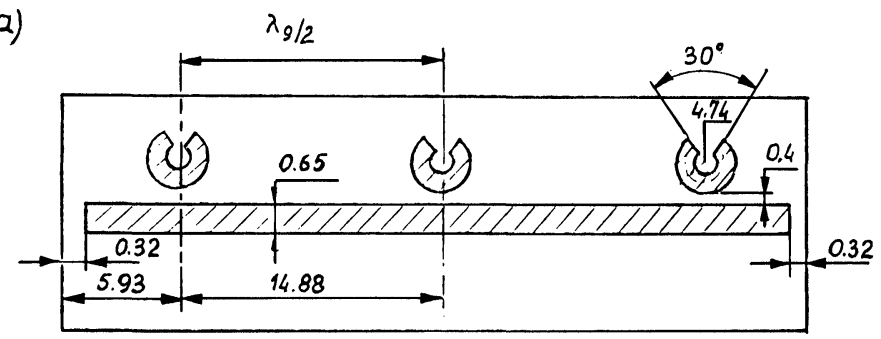

b)

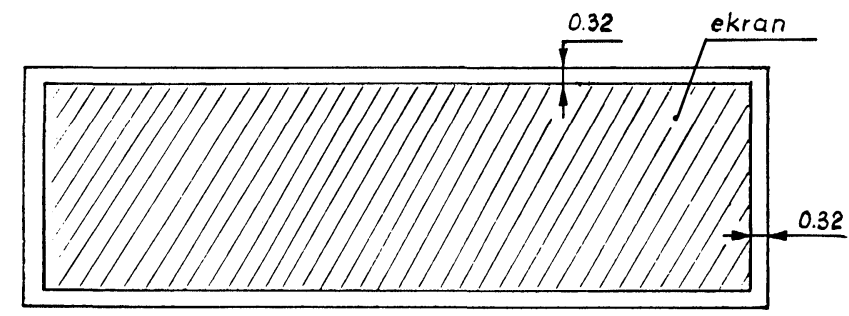

c)

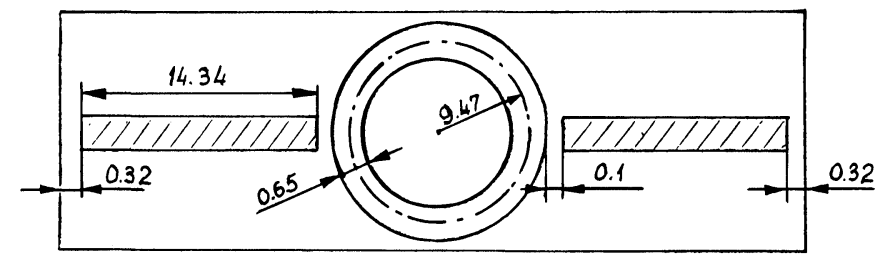

FIGURE 17 View of the ring resonators: a) for $f_{0}=9 \mathrm{GHz}$ b) Ground plane pattern c) for $f_{0}=4 \mathrm{GHz}$ 


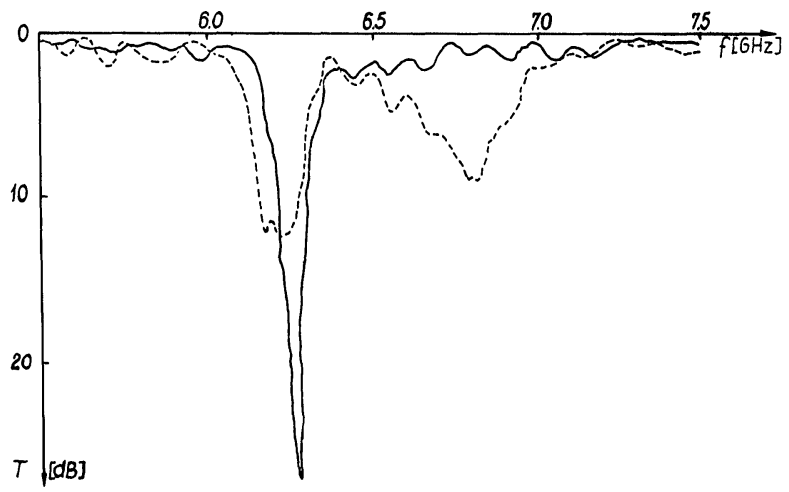

FIGURE 18 Transmittance vs Frequency Characteristic for ring resonators, $f_{0}=9 \mathrm{GHz}$.

TABLE V

Results of measurements of models of ring resonators made with the use of thick-film technology

\begin{tabular}{lcc}
\hline Parameter & $\begin{array}{l}\text { Curve no. 1 } \\
\text { (solid line) }\end{array}$ & $\begin{array}{l}\text { Curve no. 2 } \\
\text { (broken line) }\end{array}$ \\
\hline $\mathrm{f}_{0} \mathrm{GHz}$ & 6,26 & 6,22 \\
$\alpha \mathrm{dB} / \mathrm{cm}$ & 0,0787 & 0,105 \\
$\mathrm{Q}$ & 208,66 & 44,43 \\
$\Delta \mathrm{f} \mathrm{MHz}$ & 30 & 140 \\
$\lambda_{\mathrm{g}} \mathrm{cm}$ & 1,9006 & 1,913 \\
\hline
\end{tabular}

contact with the encapsulation. On the other hand, the resonators whose transmittance characteristics are shown as curve no. 1 were soldered to coaxial terminations, and the screen contacted through a special elastic conductive paste made from Du Pont produced resin. It is apparent from this how important for proper functioning of MIC circuits is the quality of the connections themselves together with their metal encapsulations.

Table VI gives a comparison of the measurement results with the values computed theoretically. Numerical values given in Table VI were computed by means of the formulae given by Schneider. ${ }^{11}$ As the author claims, these formulae approximate theoretical results to empirical results for thick-film microwave constructions.

On comparing Tables V and VI one can observe the agreement between the theoretical results and the experimental results.

Analysing the graphs given in Figure 18 one can observe that the resonant frequency of the ring resonator differs from the frequency $\mathrm{f}_{0}$ for which it was designed. The reso-

TABLE VI

Results of theoretical computation of basic parameters for ring resonators

\begin{tabular}{lcccc}
\hline Parameter & $5 \mathrm{GHz}$ & $6 \mathrm{GHz}$ & $7 \mathrm{GHz}$ & $8 \mathrm{GHz}$ \\
\hline$\alpha \mathrm{dB} / \mathrm{cm}$ & 0,054 & 0,058 & 0,064 & 0,069 \\
$\mathrm{Q}$ & 192,0 & 206,0 & 222,0 & 237,0 \\
$\Delta \mathrm{f} \mathrm{MHz}$ & 26,0 & 29,0 & 31,5 & 33,7 \\
$\lambda_{\mathrm{g}} \mathrm{cm}$ & 2,38 & 1,98 & 1,70 & 1,487 \\
\hline
\end{tabular}


nator was designed for $f_{0}=9 \mathrm{GHz}$, whereas the experimental value is $\mathrm{f}_{0}=6,26 \mathrm{GHz}$. In order to examine this problem, a complex analysis of the design method used and the influence of the technological process itself has been made. On the basis of this analysis the following conclusions have been drawn:-

An increase of resonant frequency of the ring resonator up to $5 \% \mathrm{f}_{0}$ (using alumina substrates with relative permittivity $\epsilon_{\mathrm{r}}=9,5$ and $\mathrm{h}=0,5 \mathrm{~mm}$ ) is caused by an increase in the value $\lambda_{E F}$ - due to the dispersion effect. ${ }^{2}$ According to Getsinger, ${ }^{13}$ in order to take into consideration the dispersion effect in making a design, one should introduce in the place of the effective dielectric constant $\epsilon_{\mathrm{EF}}$, the so-called real dielectric constant $\epsilon_{\mathrm{t}}$, defined by Hartwig. ${ }^{14}$

It follows ${ }^{6}$ that taking into consideration the surface covering coefficient $\mathrm{K}_{\mathrm{s}}$ in the design of a resonator causes a relative lengthening of the circumference of the ring resonator by $15-20 \%$ in relation to the previously computed one from the programme from Figure 16. It is thought that this effect is the chief cause of the increase of resonant frequency.

By way of example for the case computed in ${ }^{6}$ we obtain:-

$$
\mathrm{L}_{\mathrm{R}}=\mathrm{L} \sqrt{ } \mathrm{K}_{\mathrm{s}}
$$

where:

$\mathrm{L}_{\mathrm{R}}$ - real circumference of ring resonator

$\mathrm{L}$ - theoretically computed circumference of ring resonator

By introducing the formula to the design programme of the ring resonator we obtain:-

$$
\lambda_{0(\mathrm{emp})}=\lambda_{\mathrm{g}} \sqrt{ } \epsilon_{\mathrm{t}}, \sqrt{ } \mathrm{K}_{\mathrm{s}}
$$

Comparing both resonant frequencies, one computed theoretically without taking into consideration $\mathrm{K}_{\mathrm{s}}-\mathrm{f}_{01}$ and one computed with the coefficient $\mathrm{K}_{\mathrm{s}}-\mathrm{f}_{\mathbf{0 2}}$, we obtain-

$\mathrm{f}_{02}=\frac{\mathrm{f}_{01}}{\sqrt{ } \mathrm{K}_{\mathrm{s}}} \sqrt{\frac{\epsilon_{\mathrm{t}}}{\epsilon_{\text {ef }}}}$

For the case computed in the design we have:

Screen 220 Mesh $_{\mathrm{s}}=0,816$

Screen 330 Mesh $\mathrm{K}_{\mathrm{s}}=0,804-$ (screen used in making models of resonators)

$$
\mathrm{f}_{0 \mathrm{e}}=\frac{9}{0.804}=11,94 \mathrm{GHz}
$$

Thus it turns out that the measured frequency of the ring resonator $f_{0}=6,26 \mathrm{GHz}$ is practically the second subharmonic.

In total, the influences of the increase $\epsilon_{\mathrm{t}}$, not taking into account $\mathrm{K}_{\mathrm{s}}$ in the previous design of the ring resonator, and the tolerance of the resonator, gives a resonant frequency close to the frequency measured with an accuracy of approximately $6 \%$.

$$
\mathrm{f}_{0 \mathrm{emp}}=12,52 \mathrm{GHz} ; \mathrm{f}_{0}=11,94 \mathrm{GHz}
$$

One can see here a good agreement of the experimental results with the theoretical ones, due to the application of the new coefficient $\mathrm{K}_{\mathrm{s}}$ which takes into account, ${ }^{6}$ the discontinuous structure of thick-films. 


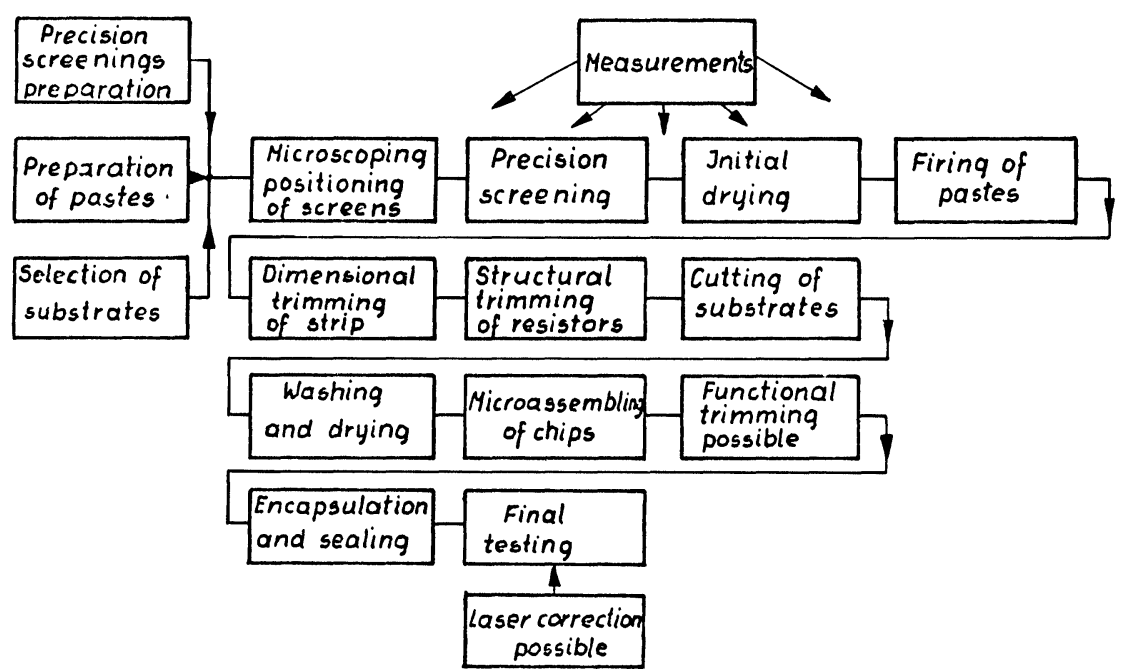

FIGURE 19 Block diagram of proposed technological process for production of thick-film MIC, ${ }^{6}$.

\subsection{NEW TECHNOLOGICAL PROCESS OF PRODUCING THICK-FILM MICS}

On the basis of the collected experimental material ${ }^{2,3,4,6}$ and a study of the literature,, 10 a new method of producing thick film ASL and MIC constructions has been evolved. Figure 19 shows a block diagram of the process.

The quality of the conductive films produced is influenced mainly by preparatory operations including screening and firing. This group of operations must be subject to special control. It is suggested that for masking the screens for precise printing in MICs, the method of indirect masking should be applied. It is also possible to use screens made of metallized net. Microscope testing of the edges of the masks obtained is indispensable. For microwave integrated circuits it is necessary to introduce topological diagrams on a scale of $25: 1$ or $50: 1$ in order to obtain an adequately small error of mapping after the reduction of the topological diagrams to scale. The threads of the metal masks stretched on a frame, should be parallel to the edge of the frames. It is not, however a critical parameter of the process because precise orientation of the threads in relation to the edge of the photographic masks produced is possible with the use of a microscope. The precision of mapping of the photographic masks on the screens has an important influence on the precision of the screening process. It is also necessary to make a precise selection of substrate plates and to prepare them properly for the printing process. The substrate material, its curvature, convexity, parallelism of surfaces, tolerance of dimensions and roughness of surface will have an influence on the quality of the printing processes. If the parameters of the plates (except roughness) enumerated above exceeds the permissible tolerance, this will cause a change of the distance between the screen and the substrate. The unstability of this parameter during the printing process results in the prints being non precise.

For MICs it is also necessary to test the thickness of the substrate. This parameter is often not met by producers. ${ }^{6}$ Variation of $h, \Delta h$, can be as high as $300 \%$ in relation to the data given in catalogues.

Measurement of the roughness of the surface of substrate plates is also essential. Contrary to the thin-film MICs, a relatively high value of the surface roughness up to the 


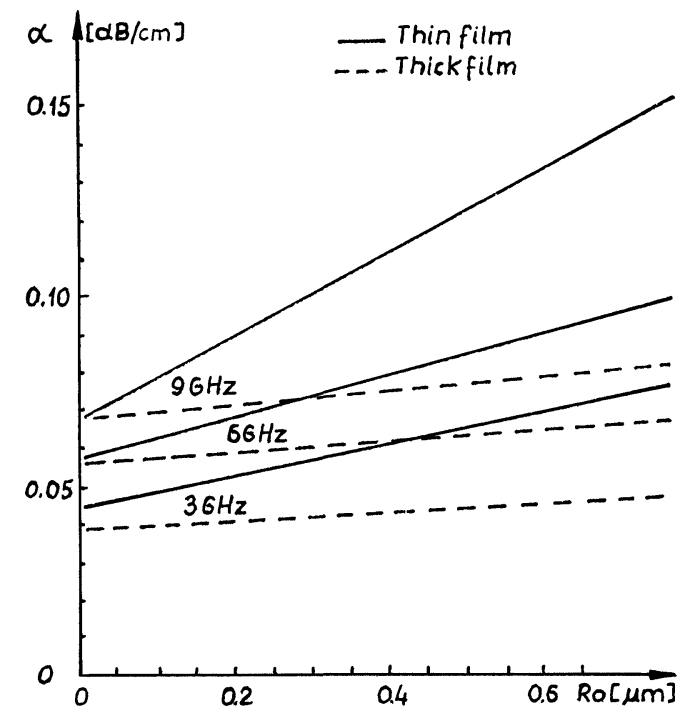

FIGURE 20 Dependance of attenuation, $\alpha$, in ASL on surface roughness, $\mathbf{R}_{\mathbf{a}}{ }^{6}$.

value of parameter $R_{a}<0,9 \mu \mathrm{m}$ does not influence in any essential way the increases of attenuation of the thick-film MICs. This is indicated by previous investigations ${ }^{5,6}$ and shown in Figure 20.

The parameter, $R_{a}$, the influences however the adhesion of the films to the substrate and the precision of making the edges of the conductive strips. Substrates with too small a value, $\mathbf{R}_{\mathrm{a}}<0,1 \mu \mathrm{m}$, (e.g. polished sapphire) are not suitable for printing MICs for all of the conductive pastes investigated. ${ }^{6}$

The binding agent in the paste, is also of interest as it is responsible, among other things, for the stability of the bonding of the fired film to the substrate. The investigation of adhesion of pastes reported by Gondek, ${ }^{6}$ on polished sapphire substrates showed that the best adhesion to smooth substrates is given by pastes containing an oxide carrier. Furthermore, investigations of adhesion made on Polish ceramic substrates $\left(96 \% \mathrm{Al}_{\mathbf{2}} \mathrm{O}_{3}\right.$, $\mathrm{R}_{\mathrm{a}}<0,9 \mu \mathrm{m}$ ) showed that the best pastes are those containing glazes plus oxides. Pastes in which the role of the carrier was played by glazes showed a somewhat smaller adhesion (ca. 20-32\%). Quite a uniform structure of the films and good adhesion was obtained for polished sapphire substrates $\left(0,1 \mu \mathrm{m}<\mathrm{R}_{\mathrm{a}}<0,4 \mu \mathrm{m}\right)$. Such substrates are therefore preferred for use in professional MICs.

Measurements have been made of the $\mathrm{Q}$ factor of ASL as a function of firing temperature using various pastes, ${ }^{5,6}$ and the results have been compared with theoretical calculations and the measurements of other authors., ${ }^{9,10}$ The curves are shown in Figure 21.

It can be seen that as far as total losses for MICs are concerned, higher temperatures of firing are more advantageous. Of course, the firing temperatures cannot be chosen abstractly. They must agree with the catalogue data given by the producers. It is always necessary however to make experimental tests in order to check if the data given by manufacturers is accurate enough.

The investigation of parameters of conductive films made by means of precise screening showed that in many cases they are not yet satisfactory for MIC constructions. Thus there is a need of improvement. Information concerning scientific research in the area of strip constructions ${ }^{2,5}$ still points to the existence of great difficulties in the precise trimming of the dimension of elements and narrow gaps. Electroerosional and 


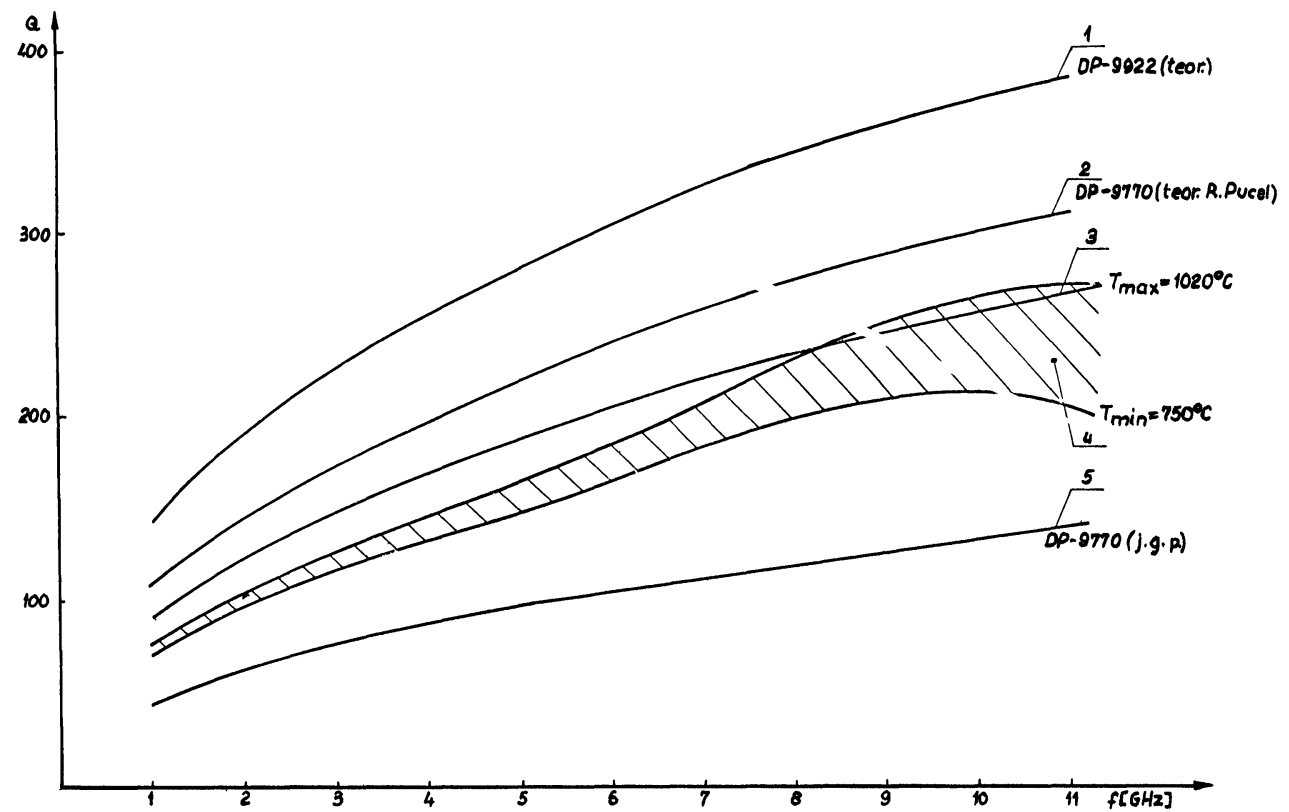

FIGURE 21 Q-factor as a function of firing temperature. Pastes: DP9770 and DP9791. Substrate: alumina ceramics $\left(96 \% \mathrm{Al}_{2} \mathrm{O}_{3}, \mathrm{Z}_{0}=50 \Omega\right)$.

1. Theoretical curve calculated according to Pucel $^{12}$ for DP9922 paste. (Du Pont; Cu paste).

2 . Theoretical curve calculated according to Pucel $^{12}$ for DP9770 paste.

3. Theoretical curve calculated according to Schneider ${ }^{11}$ for DP9770 paste.

4. Empirical curve for average value of $\alpha$, for DP9770 and DP9791 pastes.

5. Theoretical curve calculated accordingly to homogeneous density of current model, ${ }^{6}$ for DP9770 paste.

electrochemical trimming are those used most often. It has been suggested ${ }^{4,7}$ that the use of laser trimming or precise abrasive trimming could be used to accurately adjust dimensions. ${ }^{7}$ Changes in the dimensions of strip constructions will cause the change of their basic electrical parameters.

Dimensional trimming of the edges of ASL and resonators also gives a reduction in the losses connected with the emission of microwave energy. It allows a decrease of SWR, a precise "tuning in" to the resonant frequency of a chosen microwave resonator, and the improvement of transmission characteristics, $T$ vs $f(f)$, of microwave filters.

Trimming should be considered in any case at the stage of topological design. Resistive strip elements which are to work at microwave frequencies can be adjusted with the use of so-called laser structural trimming. This does not produce changes in the dimensions of strip resistors but only a change in their microstructure. Experiments in this field made in various countries ${ }^{1,5}$ are not yet satisfactory enough for this process to be generally used in the production of MICs. One can hope, however, that in the near future, after research has been made on the application of laser structural trimming to strip MIC constructions that the problem will be finally solved.

The remaining stages of the proposed method of production of thick-film MIC's are similar to those in standard thick-film technology. The only change in the process is the introduction of the laser trimming operation in the final microwave circuits. Such a possibility is only practical using laser trimming because it can be done through plates and layers protecting the microcircuits. 
3.0 COMPARISON OF ATTENUATION/vs FREQUENCY, PARAMETERS, $\alpha$, vs $\mathrm{f}(\mathrm{f})$ FOR MICs MADE WITH THE USE OF THIN AND THICK-FILM TECHNOLOGIES

On the basis of the literature studied and the present research it is possible to compare both hybrid technologies for producing MICs, namely thin and thick film technology. The comparison is made in Figure 22. In Figure 22 the graphs represent unit attenuation by ASL as a function of frequency. The graph No. 4 represents values of attenuation, $\alpha$ vs (f), obtained by the present authors for Du Pont pastes DP9770 (Pt-Ag) and DP9791 $(\mathrm{Au})$.

The parameters for ASL were computed on the basis of a new design programme ${ }^{6}$ (see Figure 16). The models of the microcircuits were made by the modified technological process (Figure 19) with the application of laser trimming of the edges. The relatively small scatter of attenuation values, $\alpha$, is evidence of the good results obtained. Graph no. 6, of Figure 22 gives the losses in ASL constructed using thin film technology. The scatter of attenuation, $\Delta \alpha$, is much higher in this case. It can be seen that the attenuation values $\alpha$ vs $=f(f)$ obtained by the present authors are acceptable for MIC hybrid constructions.

\subsection{CONCLUSIONS $2,3,4,5,6$}

On analysing the results obtained for attenuation vs frequency for thick film ASL models and other microwave elements one can state that the losses in the thick films exceed the

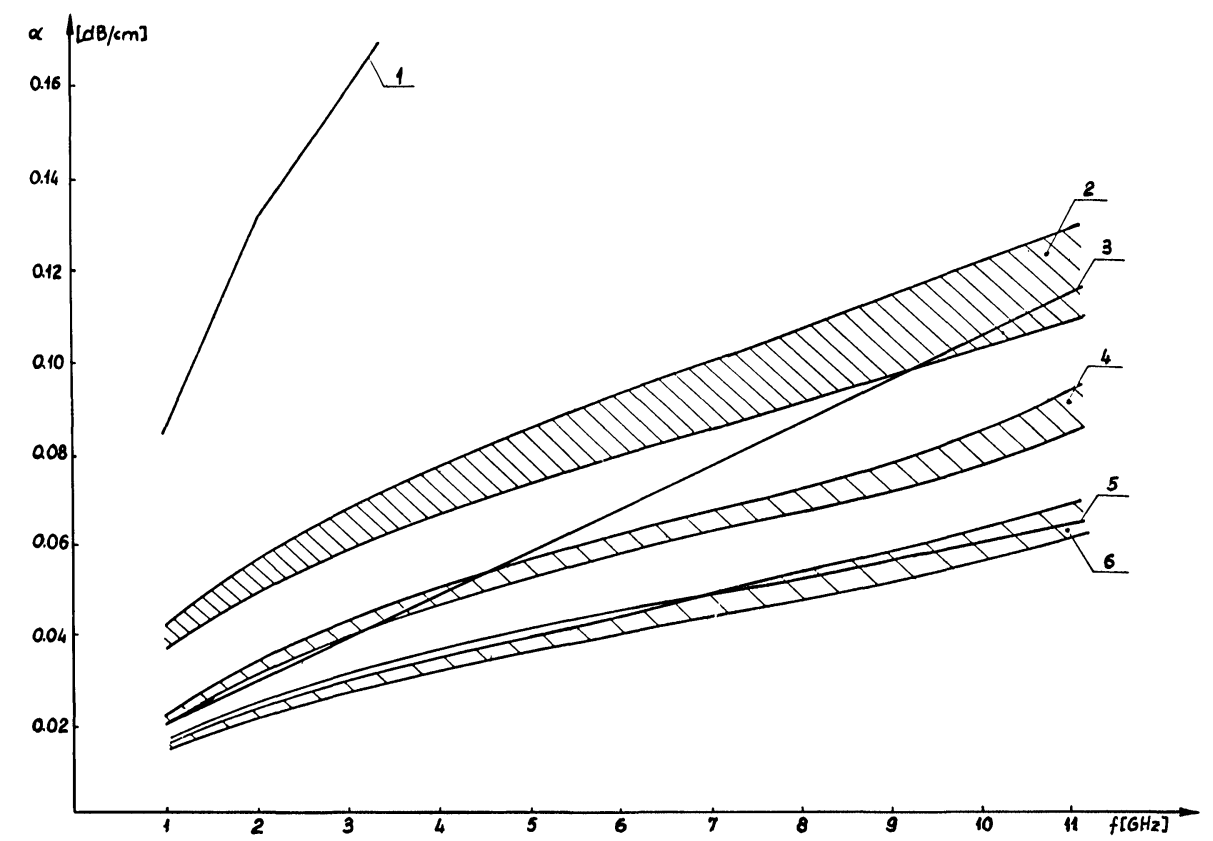

FIGURE 22 Comparison of $(\alpha)$ vs frequency, from various papers $s^{6,9,10}$

1. ASL printed by pastes: main strip EMCA 3264 + EMCA 7170, shield EMCA $3264,{ }^{9}$.

2. ASL printed by paste Engelhard T-2795, ${ }^{10}$.

3. ASL printed by paste Cermalloy $4300 \mathrm{~B}, ?$.

4. ASL printed by pastes: DP9770 and DP9791,6.

5. Theoretical curve of attenuation, of ASL, for DP9922 paste. ${ }^{6}$

6. ASL executed by thin-film technology (Cr-Cu-Au), ${ }^{10}$. 
losses in the thin films by between $30-120 \%$. This unfavourable relation for the thick-film technology results mainly from the different structure of films produced by both technologies and from the use of conductive materials. In the thin-film MIC's the following combinations of metals have been used: Ti-Au, Ta-Ti-Au, Ti-Mo-Au, $\mathrm{Cr}-\mathrm{Au}, \mathrm{Cr}-\mathrm{Cu}-\mathrm{Au}$, $\mathrm{Cr}-\mathrm{Au}-\mathrm{Cu}-\mathrm{Au}$; and in the thick-film MIC's - mainly $\mathrm{Au}$. In the present authors' opinion, the use of new copper pastes in thick-film MIC's - mainly Au. In the present authors' opinion, the use of new copper pastes in thick-film MIC's will make it possible to produce microwave circuits with parameters comparable with the results obtained for the thin film technology. This is suggested from the graph no. 5, of Figure 22. In order to achieve this goal it will be necessary still to make many tests on new materials and further to modify thick-film technology. This research, in its effect, should provide a complex solution to the problem of production of thick-film MIC's - a new generation of circuits with higher functional parameters.

\section{ACKNOWLEDGEMENTS}

The authors express their thanks to the Du Pont Company for rendering accessible the most recently produced conductive pastes for use in research.

\section{REFERENCES}

1. Fitt, J. Doctors dissertation, "The influence of the construction of thick-film resistors upon their frequency characteristics within L-band", AGH, Al. Mickiewicza 30, 30-059 Krakow, Poland, (1981).

2. Gondek, J. "The possibilities of producing thick-film microwave stripline resonators made with $\mathrm{Du}$ Pont/USA/Compositions operating within a band of 4-8 GHz - design and manufacture", Proceedings - 29th Electronic Component Conference, U.S.A. pp. 407-420, (May 1979).

3. Gondek, J., Wdjcicki, M. "Investigation into the possibilities of applying $\mathrm{Du}$ Pont conductive compositions in the production of hybrid microwave integrated circuits". (in Polish), Materials from the 2nd International Congress of Scientists of Polish Origin, Krakbw, Poland, pp. 13-26, (August 1979).

4. Gondek, J., Nowak, S. "Application of new Du Pont conductive composition in the production of thick-film wave-guides operating within a band of B $=1-5 \mathrm{GHz}$ ", (in Polish), Material from the Conference on "The Hybrid Technique for the Electronization of Poland, Krakbw, Poland, pp. 67-75, Section V. (April 1980).

5. Ca̧ber, J., Gondek, J., Wojcicki, M. "Problems occuring at the production of microwave integrated circuits and their prospects", Unpublished paper given at 16th International Society for Hybrid Microelectronics Conference, Oulu, Finland, (June 1980).

6. Gondek, J.J. Doctors dissertation. "The influence of thick-film microcircuits construction for frequential parameters of microwave asymmetrical striplines", AGH, Al. Mickiewicza 30, 30-059 Kraków, Poland, (1981).

7. Gondek, J., Nowak, S. "Method of producing passive thick-film microwave integrated circuits", P-214535, Warszawa, Poland, (1979).

8. Matthaei, G.L., Young, L., Jones, E.M. "Microwave filters, impedance matching networks and coupling structures". McGraw-Hill, New York, (1964).

9. Graves, J.F. Kline, M.D. "Platinum-palladium-gold thick-film decrease microwave solder assembly costs and improve reliability", Proceedings of the 1979 International Microelectronics Symposium, Los Angeles, U.S.A. pp. 249-253, (November 1979).

10. Hagelin, S., Wernlund, L.D. "Properties of Microstrip Transmission Lines". FOA3 - report C 3769-E2, Stockholm, Sweden, pp. 55-64, June, 1974, (obtainable from Forsvarets Forskiningsanstalt, Avdelning 3, Stockholm, Sweden).

11. Schneider, M.V. "Microstrip lines for microwave integrated circuits". The Bell Syst. Techn. I., BSTI-48, 5, (1969).

12. Pucel, R.A., Masse, D.J., Hartwig, C.P. "Losses in microstrip". IEEE Trans. on MTT, MTT-16, 6, pp. 323-350, (1968).

13. Getsinger, W.J. "Microstrip dispersion model". IEEE Trans. on MTT-21, 1, pp. 34-39, (1973).

14. Hartwig, C.P., Masse, D., Pucel, R.A. "Frequency dependent behaviour of microstrip". Int. Microwave Symp. Digest (Detroit, May 20-22, 1968), IEEE G-MTT, pp. 110-116, (1968). 

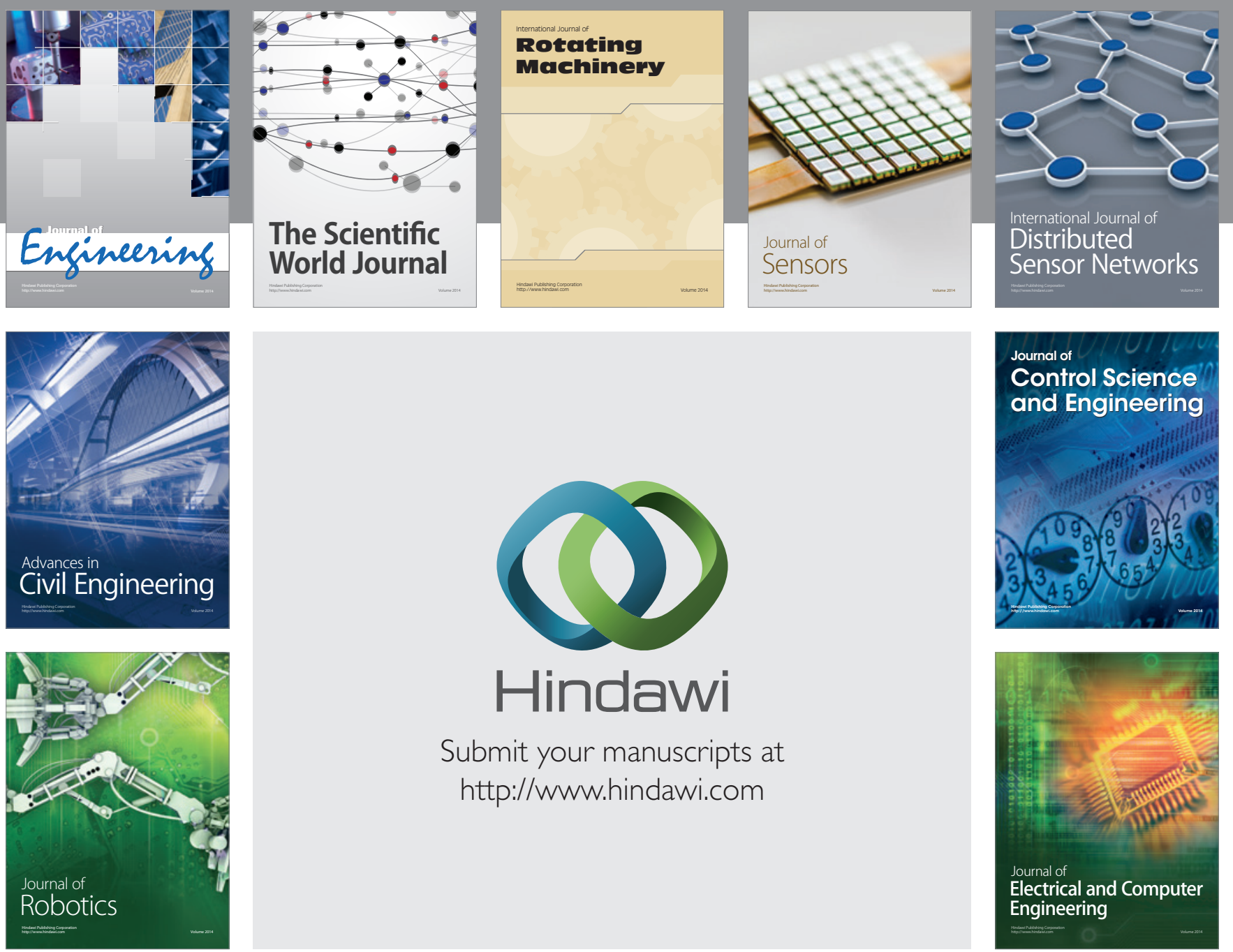

Submit your manuscripts at

http://www.hindawi.com
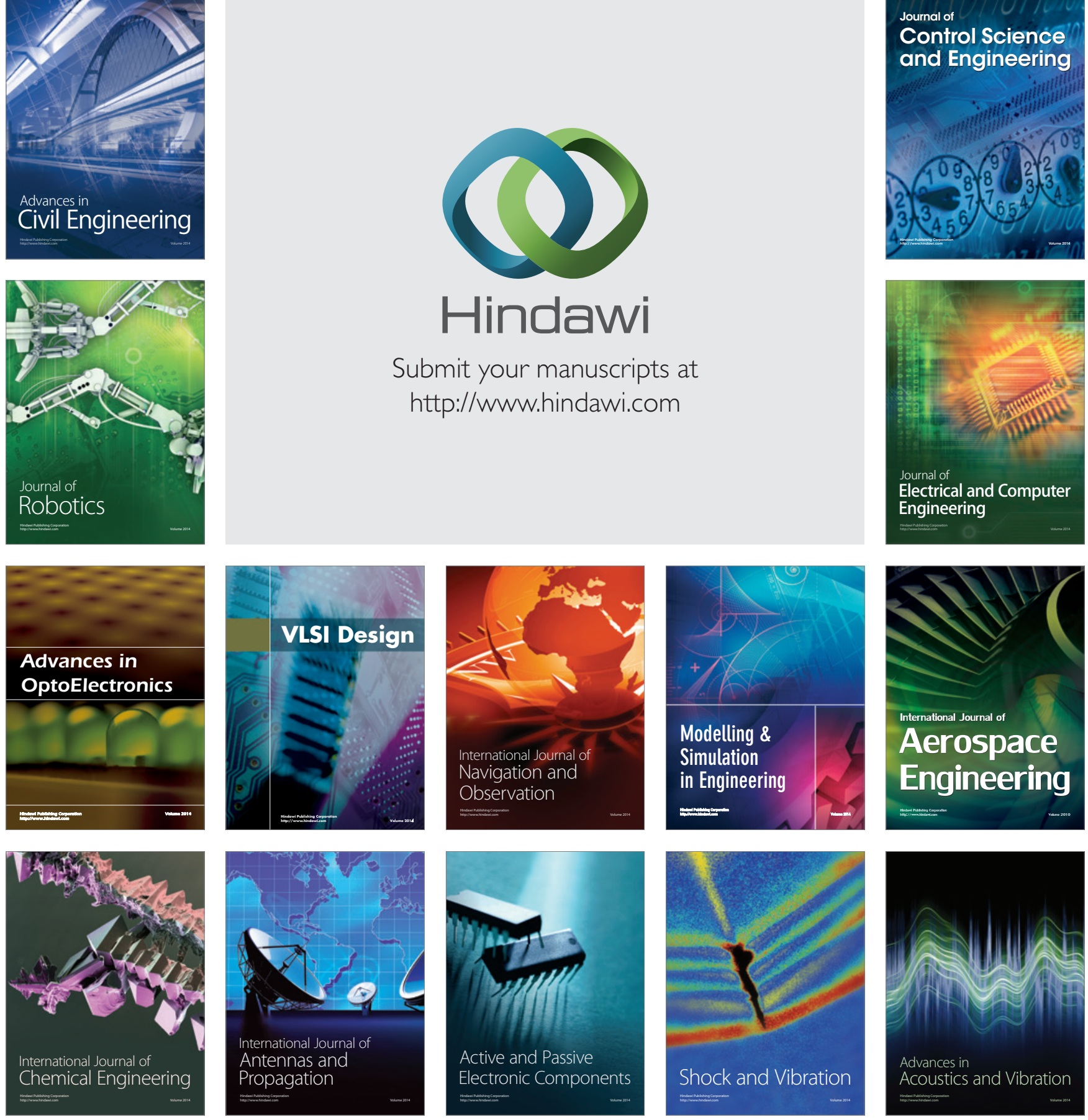